\title{
What Happens When Employees Are Furloughed? A Resource Loss Perspective
}

Journal of Career Development 2019, Vol. 46(4) 38I-394

(C) Curators of the University of Missouri 2018

Article reuse guidelines: sagepub.com/journals-permissions DOI: 10.1 I77/0894845318763880 journals.sagepub.com/home/jcd

(SAGE

\author{
Lisa E. Baranik', Janelle H. Cheung ${ }^{2}$, \\ Robert R. Sinclair ${ }^{3}$, and Charles E. Lance ${ }^{4}$
}

\begin{abstract}
Furloughs refer to placing employees on a temporary leave with no pay for the period of the leave. The current study draws from conservation of resources (COR) theory to examine how furloughs affect employees' experiences of burnout, work-family conflict, and life satisfaction. Results gathered from 212 individuals show that being furloughed during the 2013 U.S. federal government shutdown was associated with perceived personal resource loss, which was related to decreased life satisfaction and increased work-family conflict and physical, cognitive, and emotional burnout 5 weeks after the shutdown ended. The relationships between furlough status and all outcomes were fully mediated by perceived resource loss. Our findings show that furloughs can and do negatively affect employees and that these effects last long after the furlough has ended.
\end{abstract}

\section{Keywords}

furloughs, government shutdown, work-family conflict, burnout, life satisfaction, conservation of resources, job insecurity

The U.S. federal government entered a shutdown from October 1 to October 16, 2013, the third-longest government shutdown in the country's history. During the shutdown, more than 850,000 employees were furloughed, for a total of 6.6 million lost workdays (Office of Management and Budget, 2013). As a result, millions of Americans were denied critical government services and support programs, 120,000 fewer private sector jobs were created and effects such as gross domestic product growth decline, funding cuts in scientific research, and economic disruption persisted even after the shutdown ended (Office of Management and Budget, 2013).

The shutdown was one of a series of political and economic responses to the global economic downturn of 2007-2008. Although many countries now show signs of recovery from the economic

\footnotetext{
' University at Albany, Albany, NY, USA

${ }^{2}$ Oregon Health and Science University, Portland, OR, USA

${ }^{3}$ Clemson University, Clemson, SC, USA

${ }^{4}$ Organizational Research \& Development, and University of the Western Cape, Lawrenceville, GA, USA
}

\section{Corresponding Author:}

Lisa E. Baranik, Massry Center for Business, University at Albany, SUNY, Room 319, Albany, NY I2222, USA.

Email: Ibaranik@albany.edu 
downturn, increased job insecurity has been prevalent in much of the industrialized world. Given the importance of financial and economic concerns to peoples' careers, stress, and health (American Psychological Association, 2015), this downturn is arguably one of the most important recent events in the study of workplace stress management. Researchers have addressed some aspects of the economic downturn. Specifically, meta-analytic reviews have established the health-related effects of unemployment (McKee-Ryan, Song, Wanberg, \& Kinicki, 2005), underemployment (McKee-Ryan \& Harvey, 2011), and job insecurity (Sverke, Hellegren, \& Näswall, 2002). Similarly, downsizing literature shows the adverse health and well-being consequences of downsizing (Parker, Chmiel, \& Wall, 1997).

Despite their strong potential impact on workers, however, relatively little research has examined furloughs, leaving questions about the theoretical processes linking furloughs to health outcomes. This is an understandable gap, as events like government shutdowns and resulting furloughs are difficult to predict and study. In one of the few existing studies on furloughs, Halbesleben, Wheeler, and PaustianUnderdahl (2013) found that furloughs were linked to emotional exhaustion and decreased job performance. To our knowledge, however, there has been no direct test of mediating variables linking furloughs to these outcomes. Identifying the mechanisms between furloughs and employee health outcomes would allow for more refined theory development.

Our study used data collected during the 2013 U.S. government shutdown to examine personal resource loss as a mediator in the relationship between furlough status and work-family conflict, life satisfaction, and burnout 5 weeks after the shutdown ended. We tested mediating mechanisms of the resource loss process using a time-lagged design to test the relationship between furlough status and three forms of strain. Importantly, in testing this model, we utilized direct measures of actual resource loss. This is a critical step in testing the theoretical propositions of conservation of resources (COR) theory since very few studies utilizing COR theory directly measure resources. In doing so, we address multiple recommendations for extending COR theory made by Halbesleben, Neveu, PaustianUnderdahl, and Westman (2014) who noted that “the future of COR theory rests in researchers' ability to appropriately measure resources” (p. 1355).

\section{Theoretical Background and Hypothesis Development}

\section{Furloughs, Resource Loss, and Strain}

Job insecurity can be understood and defined as a work stressor, in which the anticipation and experience of an unwanted event leads to strain reactions (Lazarus \& Folkman, 1984). Although furloughs enable organizational fiscal solvency and, in the long term, save jobs, Bellairs, Halbesleben, and Leon (2014) argue that furloughs cause stress, decrease feelings of trust and justice, and change psychological contract perceptions because of the uncertainty surrounding employees' job status and income. For example, Bellairs et al. (2014) note that employees who are furloughed do not have a paycheck for an undetermined amount of time and have an unclear job status. Halbesleben et al. (2013) argue that furloughs are a unique form of job insecurity because the organization's announcement of a furlough introduces the threat of a loss of resources up until the furlough actually takes place. However, organizations often decouple announcements, resulting in a number of false alarms. As a result, employees face demands due to both the threat of the furlough and the actual furlough itself.

Following COR theory (Hobfoll, 1989, 2002), we argue that employees placed on furlough status are faced with the severe threat of resource loss both leading up to and during the actual furlough (Halbesleben, Wheeler, \& Paustian-Underdahl, 2013). Resources are defined as anything that helps individuals attain their goals (Halbesleben, Neveu, Paustian-Underdahl, \& Westman, 2014) and can include objects (e.g., a home), conditions (e.g., marital status), personal characteristics (e.g., confidence), and intrinsic and extrinsic energies (e.g., time; Hobfoll, 1989, 2002). COR theory proposes that there are two parallel mechanisms behind resource loss. The accumulation mechanism refers to using 
resources to regulate behaviors and actions in order to gain more resources, and the protection mechanism refers to actions taken to protect resources when they are threatened with resource loss, such as by investing other resources. When resources are depleted through the protection mechanism, a resource loss spiral can occur, whereby investment in critical resources becomes more and more difficult because of escalating depletion of multiple resources (Hobfoll, 1989, 2002). Furloughed employees may experience resource loss in the form of decreased pay, job security, coworker and supervisor support, and feelings of pride and success at work. Because of this, we argue that furlough status will be related to perceived personal resource loss. Personal resource loss reflects declines in individual characteristics that facilitate the stress-coping process. Examples include declines in feelings of pride and hope, reduced optimism or sense of control, and loss of a sense of purpose.

We focus on personal resource loss for a number of reasons. First, furloughs may directly cause a change in the moods and feelings of an employee (Bellairs, Halbesleben, \& Leon, 2014), and these reactions may be made worse by a decoupling effect, where employees are often warned of the possibility of a furlough but not actually put on furlough status. Therefore, when the furlough actually occurs, the loss of resources is more significant (Halbesleben et al., 2013). Second, furloughs may serve to quickly cause personal resource losses (e.g., trust) due to the sudden change in the psychological contract between the employee and the employer (Bellairs et al., 2014). For example, employee trust decreases after environmental jolts such as downsizing and sudden leadership changes (Mishra \& Spreitzer, 1998).

Furloughs represent a major stressor that affects both home and work domains, so we chose to examine outcomes that span both personal and work domains: burnout, life satisfaction, and work-life conflict. Burnout has strong theoretical connections to the resource depletion process (Hobfoll, 1989) and is negatively associated with job attitudes (Lee \& Ashforth, 1996), self-efficacy (Soji et al., 2016), and job performance (Taris, 2006). To develop hypotheses about burnout, we used the Shirom's model of burnout (Shirom, 1989; Shirom \& Melamed, 2006). The Shirom (1989) model conceptualizes burnout as a state reflecting three types of resource depletion: physical fatigue, cognitive weariness, and emotional exhaustion. Physical fatigue refers to feeling tired and having low energy levels in carrying out work tasks, cognitive weariness refers to reduced mental agility and slow thinking processes, and emotional exhaustion refers to the lack of energy to invest in interpersonal relationships with others. Job insecurity predicts burnout, but previous studies have examined severe perceptions of job insecurity, such as the fear of losing one's job (Dekker \& Schaufeli, 1995). The one study that examined burnout and furloughs as the specific form of job insecurity focused on emotional exhaustion (Halbesleben et al., 2013). It is important to examine the cognitive and physical aspects of burnout in addition to the emotional aspects, as research has found that job insecurity may be linked to cognitive and physical aspects of employee health(De Witte, 1999).

Life satisfaction focuses on the cognitive assessment of how satisfied individuals are with their life circumstances; Erdogan, Bauer, Truxillo, and Mansfield (2012) argue that more organizational studies need to be conducted on life satisfaction to contribute to one of the discipline's goals of improving people's lives. We know of no research that has been conducted on furloughs and life satisfaction; however, some research has examined the relationship between job insecurity and life satisfaction. Findings from these studies are mixed. For example, De Cuyper and De Witte (2006) found that the zero-order correlation between job insecurity and life satisfaction was not significant, but Green (2011) and Lim (1996) both identified a negative relationship.

A now substantial body of research has established links of work-family conflict with both workand family-related outcomes. Despite calls for research examining work-family conflict and job insecurity (Lewis \& Cooper, 1999), few studies have emerged on this topic and we know of no research that has been conducted on furloughs and work-family conflict. Lewis and Cooper (1999) point out that a secure income is a fundamental need of healthy families. They argue that job insecurity may 
be especially impactful on families when one member is the sole breadwinner and must withdraw from family activities because of increased work demands due to job insecurity.

Finally, we propose that personal resource loss represents a theoretical pathway linking furlough status to the three forms of strain among employees. Halbesleben et al. (2013) found that furloughs relate to negative outcomes among employees (e.g., employee emotional exhaustion and decreased job performance). Our study extends their work by identifying the reasons why furloughs have negative effects on burnout, work-family conflict, and life satisfaction. Although COR theory initially described four broad categories of resources, others have recommended different resource categorizations (ten Brummelhuis \& Bakker, 2012). The majority of work on COR theory uses a subset of resources organized according to the goals of the specific study. In the current study, we focus on personal resource loss. We argue that some resources lost during a furlough are restored after the furlough ends, such as pay. Personal resources, such as feelings of hope and optimism, are harder to restore since employees may have lingering negative feelings and thoughts about being furloughed well after the furlough has ended. Although resource loss is linked to increased strain (Hobfoll, 1989, 2002) and some studies examining the resource-strain relationship have examined mediating mechanisms of this relationship (e.g., Quiñones, Van den Broeck, \& Hans De Witte, 2013), these studies do not directly measure resource loss, meaning that few studies directly test the underlying theoretical mechanisms of COR. Consequently, the primary focus of this study was to test the following key hypotheses:

Hypothesis 1: Personal resource loss will mediate the relationship between furlough status and employee physical, cognitive, and emotional burnout.

Hypothesis 2: Personal resource loss will mediate the relationship between furlough status and life satisfaction.

Hypothesis 3: Personal resource loss will mediate the relationship between furlough status and work-family conflict.

\section{Method}

\section{Participants}

In order to participate, individuals had to be U.S. citizens, at least 18 years of age, and currently have a full- or part-time job. Informed consent was obtained before surveys were made accessible. A total of 638 participants completed the Time 1 (T1) survey, and 212 individuals completed both $\mathrm{T} 1$ and Time 2 (T2) surveys. Of the individuals who completed both surveys, a majority were aged between 25 and 34 (44\%) or between 35 and 44 (14\%), $51 \%$ were female, $81 \%$ were White, $44 \%$ were married, and the average organizational tenure was 7.3 years $(S D=7.4)$. We conducted a series of $t$ tests comparing those participants who did versus did not respond at $\mathrm{T} 2$ on all of the variables reported in Table 1. None of the $t$ tests were statistically significant at the $.01 \alpha$ level. These results are available from the first author. We also conducted Little's (1988) missing completely at random (MCAR) test, and it too indicated that the data were not significantly different from MCAR, $\chi^{2}(400)=458.09, p>.01$. As such, we used full information maximum likelihood to account for missing data which, in the present case, provides unbiased model parameter estimates (Newman, 2014).

\section{Procedure}

We surveyed American workers during the shutdown (T1) and 5 weeks after the shutdown ended (T2) using snowball sampling techniques and Mechanical Turk (MTurk) to ensure that data could be collected quickly and in the time frame of the government shutdown. The use of a prospective design with 
Table I. Study Variables' Correlations, Means, and Standard Deviations.

\begin{tabular}{lccccccccr}
\hline Variable & 1 & 2 & 3 & 4 & 5 & 6 & 7 & 8 & 9 \\
\hline I. Age (TI) & - & & & & & & & & \\
2. Gender (TI) & -.07 & - & & & & & & \\
3. Furlough status (TI) & -.04 & .06 & - & & & & & \\
4. Personal resource loss (TI) & -.01 & .01 & $.35 * *$ & .87 & & & & \\
5. Burnout: Physical (T2) & -.07 & .10 & .04 & .13 & .92 & & & \\
6. Burnout: Cognitive (T2) & -.07 & $.19 *$ & .09 & .11 & $.72^{* *}$ & .90 & & \\
7. Burnout: Emotional (T2) & -.01 & -.03 & .12 & $.23^{* *}$ & $.60^{* *}$ & $.62^{* *}$ & .93 & & \\
8. Work-family conflict (T2) & .12 & .05 & .07 & .13 & $.46^{* *}$ & $.43^{* *}$ & .33 & .87 & \\
9. Life satisfaction (T2) & .03 & .05 & -.10 & $-.31^{* *}$ & $-42^{*}$ & $-.39 * *$ & $-.40^{* *}$ & $-.34^{*}$ & .91 \\
$M$ & 2.61 & 1.50 & 1.26 & 2.18 & 2.87 & 2.57 & 2.12 & 2.81 & 3.33 \\
SD & 1.26 & .50 & .44 & 1.09 & .89 & .86 & .91 & .97 & .98 \\
\hline
\end{tabular}

Note. Age was coded as I $=I 8-24,2=25-34,3=35-44,4=45-54,5=55-64,6=65-74$, and $7=75+$. Gender was coded as $\mathrm{I}=$ male and $2=$ female. Furlough status was coded as $\mathrm{I}=$ no and $2=$ yes. Sample sizes ranged from I 79 to 395 . Coefficient $\alpha \mathrm{s}$ are reported on the diagonal. $\mathrm{TI}=$ Time I; T2 $=$ Time $2 ; S D=$ standard deviation; $M=$ mean.

$*_{p}<.05 . * * p<.01$.

a 5-week gap between the assessment of the predictors and mediators with the outcomes offers somewhat stronger support for temporal precedence than cross-sectional designs (Shadish, Cook, \& Campbell, 2002). Recruiting efforts were directed toward furloughed employees (e.g., e-mail subject lines to participants read "Affected by the Government Shutdown?"). Participants were entered into a drawing to win US\$50 at both T1 and T2.

\section{Measures}

Furlough status (T1) was measured with a single item asking if the government shutdown had caused the participant to be furloughed for 1 day or more. Data were collected during the latter part of the shutdown, from October 6 through 16, and thus participants had been furloughed between 1 and 6 days. Because government shutdowns are unpredictable, furloughed participants did not know when they would be returning to work. Twenty-six percent of participants were furloughed for at least 1 day.

Personal resource loss (T1) was assessed using 4 items from the conservation of resources evaluation (COR-E; Hobfoll \& Lilly, 1993). Although the full COR-E has been used in some studies, the scale contains 74 items. As such, consistent with past researchers (e.g., deRoon-Cassini, St. Aubin, Valvano, Hastings, \& Horn, 2009), we selected a subset of the scale. Similar to Hobfoll, Hall, and Canetti (2012), we focused on personal resource loss items: "Feeling that my future success depends on me," "Sense of optimism," "Feeling that I have control over my life," and "Feeling that my life has meaning/purpose." Participants were asked "to what degree have you lost any of the following things as a result of the government shutdown?" $(1=$ not at all to $5=$ a great degree $)$. Past research has supported the validity of the personal resource loss items from the COR-E, showing that they correlate in expected ways with psychological distress, health, post-traumatic stress disorder, and depression (Hobfoll, Hall, \& Canetti, 2012; Hobfoll, Tracy, \& Galea, 2006). Because we selected a unique subset of the items, we conducted a confirmatory factor analysis to examine their unidimensionality. The one-factor confirmatory model of the 4 items had good model fit: $\chi^{2}(2)=21.23$, Tucker-Lewis index $=.95$, comparative fit index $=.98$, and standardized root mean squared residual $=.02$. Coefficient $\alpha$ was .87 .

Burnout (T2) was measured using the Shirom-Melamed Burnout Measure (SMBM; Shirom \& Melamed, 2006). The scale contains 3 items for each dimension, including physical fatigue (e.g., "I felt physically drained"), cognitive weariness (e.g., "My thinking process was slow"), and emotional 
Table 2. Structural Model for Overall Goodness-of-Fit Indices.

\begin{tabular}{|c|c|c|c|c|c|c|c|}
\hline Model & $\chi^{2}$ & $d f$ & RMSEA & TLI & $\mathrm{CFI}$ & $\Delta \chi^{2}$ & $\Delta d f$ \\
\hline I. Complete mediation & $793.70 * *$ & 305 & .070 & .841 & .861 & & \\
\hline I Versus 2 & & & & & & 1.18 & 5 \\
\hline $\begin{array}{l}\text { 2. Partial mediation } \\
\text { I Versus } 3\end{array}$ & $792.52 * *$ & 300 & .071 & .838 & .860 & $193.36 * *$ & 3 \\
\hline 3. Final model & $600.34^{* *}$ & 302 & .040 & .928 & .938 & & \\
\hline
\end{tabular}

Note. $\Delta \chi^{2}$ and $\Delta d f$ are difference $\chi^{2}$ and $d f$, respectively. RMSEA = root mean squared error of approximation; TLI $=$ TuckerLewis index; $\mathrm{CFI}=$ comparative fit index; $d f=$ model degrees of freedom.

$* * p<.01$.

exhaustion (e.g., "I have been unable to invest emotionally in coworkers, customers, or patients"). Participants were asked to indicate how often they experienced each of the items over the past 30 days $(1=$ never to $5=$ always $)$. Supporting the validity of the scales, Barber and Santuzzi (2015) found that all three subscales of the SMBM were correlated in expected ways with stressors (e.g., lack of control) and strain variables (e.g., sleep, presenteeism, and absenteeism). The coefficient $\alpha$ was .92 for physical burnout, .90 for cognitive burnout, and .93 for emotional burnout.

Satisfaction with life (T2) was measured using the 5-item Satisfaction with Life Scale developed by Diener, Emmons, Larsen, and Griffin (1985). This scale is widely used and several studies support its validity (e.g., Pavot, Diener, Colvin, \& Sandvik, 1991). Participants were asked to what extent they agreed or disagreed with statements about their lives (e.g., "I am satisfied with my life"; $1=$ strongly disagree to $5=$ strongly agree $)$. Coefficient $\alpha$ was .91 .

Work-family conflict (T2) was measured using Carlson and Frone's (2003) 6-item scale to assess work to family internal and external conflict. Participants were asked to indicate how often they experienced work-family conflict $(1=$ never to $5=$ always $)$. A sample item was "Today, my job interfered with my home life.” Research (e.g., Wang, Liu, Zhan, \& Shi, 2010) has found that Calson and Frone's (2003) measure of work-family conflict is related to theoretically meaningful variables, such as alcohol abuse, thus supporting the scale's nomological validity. Coefficient $\alpha$ was .87 .

Age and gender (T1) were used as control variables in all analyses described below. Age was used since it is a well-known predictor of career status and health, and gender was used since men and women tend to have differences in responsibilities at work and at home, which can impact how occupational health issues are experience and addressed (Messing et al., 2003).

\section{Results}

Descriptive statistics and correlations are shown in Table 1. Almost all of the correlations between age and gender and our study's substantive variables were not different from 0 . Still, we included them as control variables so as to correct for their potential spurious influence on the main results, as both age and gender tend to be associated with health. As expected, being furloughed was positively correlated with reporting more personal resource loss $(r=.35)$. Personal resource loss was positively correlated with emotional burnout $(r=.23)$ and negatively correlated with life satisfaction $(r=-.31)$. Correlations between personal resource loss and physical burnout, cognitive burnout, and work-family conflict were in the expected direction but were not statistically significant.

In order to test our study's main hypotheses, we used Mplus, Version 7, to test three alternative structural equation models using individual items as manifest indicators. First, we tested a complete mediation model $\left(M_{1}\right)$ in which all of the effects of furlough status on employee outcomes (burnout, work-family conflict, and life satisfaction) were mediated by resource loss. The overall fit of this model to the data was relatively poor (Table 2). Second, we tested a partial mediation model $\left(M_{2}\right)$ in which direct effects 


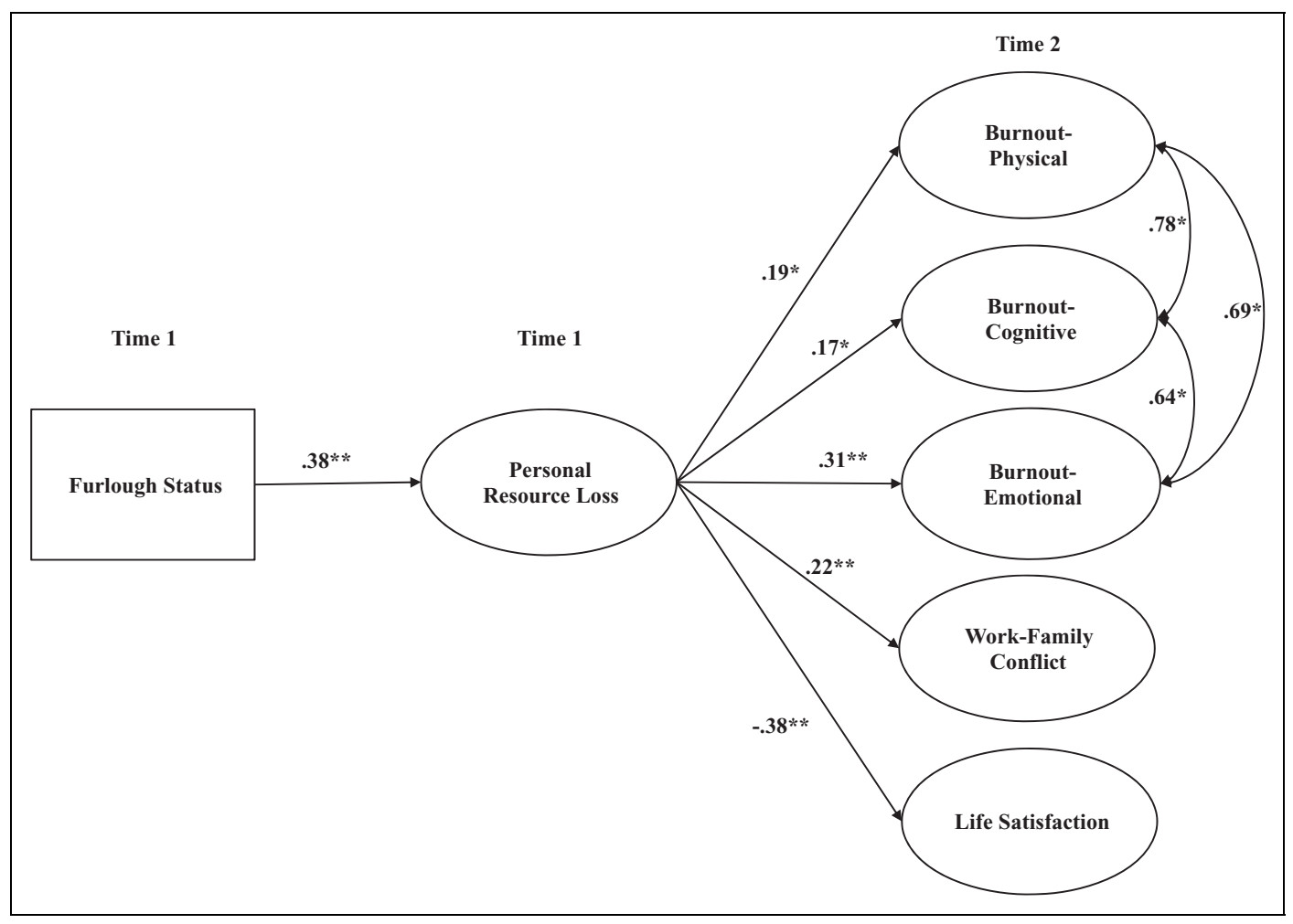

Figure I. Standardized structural equation model results with personal resource loss as a mediator of the relationship between furlough status and burnout dimensions (physical, cognitive, and emotional), work-family conflict, and satisfaction with life. All coefficients are significant at $p<.05$.

were estimated from furlough status to employee outcomes in addition to the indirect effects specified in $M_{1}$. A $\chi^{2}$ difference test (Table 2) showed that $M_{2}$ fit no better than $M_{1}$, indicating that all effects of furlough status were mediated by resource loss (see James, Muliak, \& Brett, 2006).

Although burnout is known to be multidimensional and hierarchical with a generalized burnout factor at the top of the hierarchy (Shirom \& Melamed, 2006), this structure was not incorporated into either $M_{1}$ or $M_{2}$. Recognizing this unmodeled structure by including covariances among the burnout variables' disturbances in a third, final model $\left(M_{3}\right)$ improved model fit considerably, $\Delta \chi^{2}(3)=$ 193.36, $p<.01$, with model fit meeting or exceeding cutoff values that are often used to judge good model fit (Lance, Butts, \& Michels, 2006). In particular, McDonald and Ho's (2002) root mean squared error of approximation for the path portion of the overall model $(p=.04)$ indicated that the structural (theoretical) portion of the model exhibited a good fit to the data independent of the fit of the measurement (operational) portion of the model (Williams \& O’Boyle, 2011). Standardized structural model parameter estimates for this model are shown in Figure 1. To complement earlier tests of model fit, we also specified for tests of indirect effects. As expected, $\beta$ s for the indirect effects show that employees who were furloughed reported higher levels of perceived resource loss and that resource loss was, in turn, positively related to work-family conflict $(\beta=.08, p<.05)$ and the physical $(\beta=.07, p<.05)$, cognitive $(\beta=.06, p<.05)$, and emotional $(\beta=.12, p<.05)$ forms of burnout and negatively related to life satisfaction $(\beta=-.14, p<.05)$, thus supporting our hypotheses that resource loss would mediate the relationship between furlough status and employee burnout, life satisfaction, and work-family conflict. 


\section{Discussion}

In the current study, we focused on employees' experiences of furloughs during a government shutdown. Although not as severe or pervasive as other forms of job insecurity, such as downsizing and underemployment, furloughs are frequently used by both the public and private sector. There is virtually no research examining the impact of furloughs on employees (see Halbesleben et al., 2013, for an exception), leaving unanswered questions for organizations and managers regarding how furloughs relate to employee well-being. Findings from the current study show that furloughs are related to personal resource loss, which is in turn related to increased burnout, increased workfamily conflict, and decreased life satisfaction 5 weeks after the furlough ended. Personal resource loss fully mediated these relationships. Building on Halbesleben et al.'s (2013) previous work that identified emotional exhaustion as an outcome of furloughs, the current study is the first to pinpoint personal resource loss as a mediating variable in the furlough-burnout relationship. The current study is also the first to identify furlough status as a predictor of other strain variables including work-family conflict, life satisfaction, and the physical and cognitive aspects of burnout.

Our study responds to recommendations to move COR theory (Hobfoll, 1989, 2002) forward by directly measuring perceived resource loss as it unfolds (Halbesleben et al., 2014). In the current study, we used 4 items from Hobfoll and Lilly's (1993) COR-E to measure personal resources. As compared with other stress studies using COR theory to account for the relationship between stressors and health, but that do not directly measure resource loss as a mechanism, our approach offers a stronger test of COR propositions. These findings support the utility of obtaining direct measures of resource loss and offer more support for COR theory than studies that do not employ measures of resource loss.

One of the main assumptions of COR theory (Hobfoll, 1989, 2002) is that individuals seek to retain and protect resources when they are at risk of losing them. When coping with resource loss is unsuccessful, individuals experience stress. We show that being put on furlough status is associated with a loss of personal resources, and as predicted by COR theory, this loss of personal resources was associated with strain indicators including burnout, work-family conflict, and decreased life satisfaction. COR theory describes the concept of a loss spiral, in which a lack of resources leads to stress, and stress, in turn, makes it more difficult to accumulate resources. The current study shows evidence for the beginning of a loss cycle associated with being placed on furlough status. Furloughs are associated with burnout, work-family conflict, and decreased life satisfaction because of the loss of personal resources they engender, making it more difficult to deal with stressful situations in their work and home lives.

In further recognition of the importance of personal resources, ten Brummelhuis and Bakker (2012) suggest that personal resources are the key resource in their proposed work-home resources model, whereby gains and losses in personal resources across work and family determine whether employees experience work-family enrichment or work-family conflict. Thus, while trying to understand employees' experiences of furloughs, it is important to consider that the negative effects of furloughs in both work and home domains can continue long after the furlough has ended. For example, even after a furlough has ended, employees may have lingering thoughts and emotions related to concerns about job stability and trust in their employer or may be overwhelmed at work trying to catch up from time lost during the furlough, both of which can spill over into the home domain.

We found that the mean of the personal resource loss measure was somewhat low $(2.18$ on a 5-point scale). This suggests that, in general, our sample reported relatively low levels of personal resource loss because of the government shutdown. We know of one other study (Hobfoll et al., 2012) that has linked personal resource loss to psychological distress and poor subjective health, but participants were Palestinian adults living in the West Bank, Gaza Strip, and East Jerusalem and were exposed to major stressors, such as political violence. Our findings show that, even at low levels, personal resource loss was significantly related to health outcomes. One would expect even 
stronger findings in circumstances where participants experience more resource loss than those in our sample. Whereas government employees in the shutdown experienced furloughs, employees facing more chronic job insecurity stressors such as unemployment and underemployment might experience even higher levels or longer lasting periods of resource loss - an explanation that would support the extensive literature linking employment stressors to health and well-being outcomes (McKee-Ryan \& Harvey, 2011).

\section{Implications for Practice}

Organizational intervention efforts need to focus on providing employees with resources to cope with the strain associated with the furlough and manage threats of resource loss from an anticipated furlough. Sinclair, Sears, Probst, and Zajack (2010) drew from a public health perspective (cf. Tetrick \& Quick, 2011) to suggest three levels of potential intervention for economic stressors such as furloughs: primary, secondary, and tertiary. Such interventions should be appropriate for both those who have been furloughed (or experiencing job insecurity) and those who were not furloughed themselves but experienced adverse consequences because of the lost access to those who were furloughed or their own concerns about being furloughed.

Primary prevention concerns preventing problems before they occur and is typically aimed at populations as a whole (e.g., all employees in an organization). Primary prevention programs should aim to create a supportive organizational climate for all workers prior to any risks of potential furloughs. For example, research on perceived organizational support has established the benefits of providing resources such as fair treatment, adequate compensation, and supportive supervision (Rhoades \& Eisenberger, 2002). Organizations also can help employees develop their personal resources through strategies such as coaching, a team climate, and facilitating autonomy (Xanthopoulou, Bakker, Demerouti, \& Schaufeli, 2009). Bellair et al. (2014) further recommended commitment human resources systems as a method for organizations to best endure furloughs, as they allow focus on shaping employee behavior through trust and allowing employees to have autonomy and flexibility in their jobs.

Secondary prevention involves treating employees at risk of potential problems such as employees anticipating a potential furlough. For such employees, we advise organizations to more directly help employees manage the impact of a potentially impending furlough. Clear communication with employees to inform and reassure them about the future may be helpful by reducing employees' sense that their futures are threatened and increasing their confidence that they will be able to recover lost resources. Employers also may be able to have employees protect against potential resource loss through secondary prevention steps such as providing financial education and counseling to employees who may lose pay during the furlough and providing realistic previews about potential furlough-related consequences.

Finally, tertiary prevention involves efforts to prevent further damage and restore employees to full health after a furlough such as through providing employees with resources needed to recover from the furlough and to rebuild trust in the organization. Furloughs undermine employee confidence in the organization and efforts to respond to the resource draining effects of furloughs do not end simply because the furlough ends. Restoring trust is likely to be central to this process, as furloughs are most likely to be seen as a breach of employees' expectations about their employment relationship (Robinson, 1996). Although compensating employees for lost wages would be ideal, it may be unrealistic and therefore resource restoration efforts probably need to focus on employees' socioemotional needs.

\section{Limitations}

The study reported here was a natural experiment, a strong research design and a rarity in behavioral research (Shadish et al., 2002), but one inherent limitation to this design was that we relied on a 
convenience sample that may limit the generalizability of our findings. However, as Landers and Behrend (2015) note, virtually all organizational samples are convenience samples and using this method allowed us to quickly recruit employees who were furloughed. Another limitation was that furlough status, resource loss, and outcome measures were all obtained using a single source-self-report. In the present case, however, furlough status was a potentially verifiable, objective public event where there is little or no opportunity for bias. Additionally, resource loss and strain and satisfaction outcomes are private events (Skinner, 1957) that may only be accessed through reports of the one that experiences them. We took one of the strongest precautions against common method bias by using a 5-week gap in between the measurement of resource loss and outcomes (Conway \& Lance, 2010). As such, we feel that there was little chance that method bias posed a threat to the integrity to our findings.

The correlations between furlough status (the antecedent variable) with the outcome variables of burnout, life satisfaction, and work-family conflict were not significantly different from 0 . The establishment of a relationship between an antecedent variable and outcome variables was once regarded as a first step in testing for mediation (Baron \& Kenny, 1986). However, Kenny, Kashy, and Bolger (1989, p. 260) rescinded this requirement, and it is now widely regarded as an unnecessary and potentially misleading step in testing for mediation (James et al., 2006). Indeed, researchers who adhere rigidly to the Baron and Kenny's (1986) causal steps procedure for testing mediation may fail to detect a mediated relation that is actually present by relying on this first step. As a final limitation, in testing mediation in the current study, we did not control for the health outcomes thus limiting our ability to draw strong causal inferences from the data.

\section{Future Research Directions}

Future studies should continue to directly test the theoretical mechanisms of COR theory by using the personal resource measure developed in the current study. Additionally, future studies should focus on the experiences of furloughed workers by investigating coping mechanisms and objective health outcomes. For example, Cotter and Fouad (2013) identified social support as an important protective factors for individuals who experienced layoffs. Future research could examine different forms of support including supervisor support, coworker support, and family support in addition to other supportive relationships, such as mentoring relationships. More work should be done to build on the small body of literature that has examined the impact of large-scale political and societal events such as government shutdowns, terrorist attacks, wartimes, and other financial and economic jolts on employees. Bellairs et al. (2014) propose a theoretical model whereby jolts lead to furloughs, which in turn lead to employee affective and behavioral responses. Future research should continue to examine components of this model, focusing on how furloughs affect employee behaviors such as turnover intentions, counterproductive work behaviors, and job attitudes. It would be particularly useful for future research to be longitudinal, rather than simply lagged, so that researchers can better pinpoint causal order and direction involving resource loss and resource gain spirals.

\section{Authors' Note}

Charles E. Lance is now affiliated to Organizational Research \& Development, and University of the Western Cape.

\section{Declaration of Conflicting Interests}

The author(s) declared no potential conflicts of interest with respect to the research, authorship, and/or publication of this article.

\section{Funding}

The author(s) received no financial support for the research, authorship, and/or publication of this article. 


\section{References}

American Psychological Association. (2015). Stress in America: Paying with our health. Retrieved from http:// www.apa.org/news/press/releases/stress/2014/stress-report.pdf

Barber, L. K., \& Santuzzi, A. M. (2015). Please respond ASAP: Workplace telepressure and employee recover. Journal of Occupational Health Psychology, 20, 172-189.

Baron, R. M., \& Kenny, D. A. (1986). The moderator-mediator distinction in social psychological research: Conceptual, strategic, and statistical considerations. Journal of Personality and Social Psychology, 51, 1173-1182.

Bellairs, T., Halbesleben, J. R. B., \& Leon, M. R. (2014). A multilevel model of strategic human resource implications of employee furloughs. In T. Bellairs, J. R. B. Halbesleben, \& M. R. Leon (Eds.), Research in personnel and human resources management (pp. 99-146). Bingley, UK: Emerald Group.

Carlson, D. S., \& Frone, M. R. (2003). Relation of behavioral and psychological involvement to a new four-factor conceptualization of work-family interference. Journal of Business and Psychology, 17, 515-535. doi:10. 1023/A:1023404302295

Conway, J. M., \& Lance, C. E. (2010). What reviewers should expect from authors regarding common method bias in organizational research. Journal of Business and Psychology, 25, 325-334. doi:10.1007/s10869-010-9181-6

Cotter, E. W., \& Fouad, N. A. (2013). Examining burnout and engagement in layoff survivors: The role of personal strengths. Journal of Career Development, 40, 424-444.

De Cuyper, N., \& De Witte, H. (2006). The impact of job insecurity and contact type on attitudes, well-being, and behavioral reports: A psychological contract perspective. Journal of Occupational and Organizational Psychology, 79, 395-409.

De Witte, H. (1999). Job insecurity and psychological well-being: Review of the literature and exploration of some unresolved issues. European Journal of Work and Organizational Psychology, 8, 155-177.

Dekker, S. W. A., \& Schaufeli, W. B. (1995). The effects of job insecurity on psychological health and withdrawal: A longitudinal study. Australian Psychologist, 30, 57-63.

deRoon-Cassini, R. A., St.Aubin, E., Valvano, A., Hastings, J., \& Horn, P. (2009). Psychological well-being after spinal cord injury: Perception of loss and meaning making. Rehabilitation Psychology, 54, 306-314.

Diener, E., Emmons, R. A., Larsen, R. J., \& Griffin, S. (1985). The satisfaction with life scale. Journal of Personality Assessment, 49, 71-75. doi:10.1207/s15327752jpa4901_13

Erdogan, B., Bauer, T., Truxillo, D. M., \& Mansfield, L. R. (2012). Whistle while you work: A review of the life satisfaction literature. Journal of Management, 38, 1038-1083. doi:10.1177/0149206311429379

Green, F. (2011). Unpacking the misery multiplier: How employability modifies the impacts of unemployment and job insecurity on life satisfaction and mental health. Journal of Health Economics, 30, 265-276.

Halbesleben, J. R. B., Neveu, J. P., Paustian-Underdahl, S. C., \& Westman, M. (2014). Getting to the COR: Understanding the role of resources in conservation of resources theory. Journal of Management, 40, 1334-1364. doi: $10.1177 / 0149206314527130$

Halbesleben, J. R. B., Wheeler, A. R., \& Paustian-Underdahl, S. C. (2013). The impact of furloughs on emotional exhaustion, self-rated performance, and recovery experiences. Journal of Applied Psychology, 98, 492-503. doi: $10.1037 / \mathrm{a} 0032242$

Hobfoll, S. E. (1989). Conservation of resources: A new attempt at conceptualizing stress. American Psychologist, 44, 513-524. doi:10.1037/0003-066X.44.3.513

Hobfoll, S. E. (2002). Social and psychological resources and adaptation. Review of General Psychology, 6, 307-324. doi:10.1037/1089-2680.6.4.307

Hobfoll, S. E., Hall, B. J., \& Canetti, D. (2012). Political violence, psychological distress, and perceived health: A longitudinal investigation in the Palestinian Authority. Psychological Trauma: Theory, Research, Practice, and Policy, 4, 9-21. doi:10.1037/a0018743

Hobfoll, S. E., \& Lilly, R. S. (1993). Resources conservation as a strategy for community psychology. Journal of Community Psychology, 21, 128-148. doi:10.1002/1520-6629(199304)21:2<128::AID-JCOP2290210206>3. 0.CO;2-5 
Hobfoll, S. E., Tracy, M., \& Galea, S. (2006). The impact of resource loss and traumatic growth on probably PTSD and depression following terrorist attacks. Journal of Traumatic Stress, 19, 867-878.

James, L. R., Mulaik, S. A., \& Brett, J. M. (2006). A tale of two methods. Organizational Research Methods, 9, 233-244.

Kenny, D. A., Kashy, D. A., \& Bolger, N. (1989). Data analysis in social psychology. In D. Gilbert, S. T. Fiske, \& G. Lindzey (Eds.), Handbook of social psychology (Vol. 1, pp. 233-265). New York, NY: McGraw-Hill.

Lance, C. E., Butts, M. M., \& Michels, L. C. (2006). The sources of four commonly reported cutoff criteria: What did they really say? Organizational Research Methods, 9, 202-220. doi:10.1177/1094428105284919

Landers, R. N., \& Behrend, T. S. (2015). An inconvenient truth: Arbitrary distinctions between organizational, Mechanical Turk, and other convenience samples. Industrial and Organizational Psychology: Perspectives on Science and Practice. doi:10.1017/iop.2015.13

Lazarus, R. S., \& Folkman, S. (1984). Stress, appraisal, and coping. New York, NY: Springer.

Lee, R. T., \& Ashforth, B. E. (1996). A meta-analytic examination of the correlates of the three dimensions of job burnout. Journal of Applied Psychology, 81, 123-133. doi:10.1037/0021-9010.81.2.123

Lewis, S., \& Cooper, C. L. (1999). The work-family research agenda in changing contexts. Journal of Occupational Health Psychology, 4, 382-393.

Lim, V. K. G. (1996). Job insecurity and its outcomes: Moderating effects of work-based and nonwork-based social support. Human Relations, 49, 171-194.

Little, R. J. A. (1988). A test of missing completely at random for multivariate data with missing values. Journal of the American Statistical Association, 404, 1198-1202.

McDonald, R. P., \& Ho, M. (2002). Principles and practice in reporting structural equation analyses. Psychological Methods, 7, 64-82. doi:10.1037/1082-989X.7.1.64

McKee-Ryan, F. M., \& Harvey, J. (2011). "I have a job, but ... ": A review of underemployment. Journal of Management, 37, 962-996. doi:10.1177/0149206311398134

McKee-Ryan, F. M., Song, Z., Wanberg, C. R., \& Kinicki, A. J. (2005). Psychological and physical well-being during unemployment: A meta-analytic study. Journal of Applied Psychology, 90, 53-76.

Messing, K., Punnett, L., Bond, M., Alexanderson, K., Pyle, J., Zahm, S., . . de Grosbois, S. (2003). Be the fairest of them all: Challenges and recommendations for the treatment of gender in occupational health research. American Journal of Industrial Medicine, 43, 618-629.

Mishra, A. K., \& Spreitzer, G. M. (1998). Explaining how survivors respond to downsizing: The roles of trust, empowerment, justice, and work redesign. Academy of Management Review, 23, 567-588.

Newman, D. A. (2014). Missing data: Five practical guidelines. Organizational Research Methods, 17, 372-411. doi: 10.1177/1094428114548590

Office of Management and Budget. (2013). Impact and costs of the 2013 federal government shutdown. Retrieved June 19, 2015, from http://www.whitehouse.gov/sites/default/files/omb/reports/impacts-and-costs-of-october2013-federal-government-shutdown-report.pdf

Parker, S. K., Chmiel, N., \& Wall, T. D. (1997). Work characteristics and employee well-being within a context of strategic downsizing. Journal of Occupational Health Psychology, 2, 289-303.

Pavot, W., Diener, E., Colvin, R., \& Sandvik, E. (1991). Further validation of the Satisfaction with Life Scale: Evidence for the cross-method convergence of well-being measures. Journal of Personality Assessment, 57 , 149-161.

Quiñones, M., Van den Broeck, A., \& De Witte, H. (2013). Do job resources affect work engagement via psychological empowerment? A mediation analysis. Journal of Work and Organizational Psychology, 29, 127-134.

Rhoades, L. R., \& Eisenberger, R. (2002). Perceived organizational support: A review of the literature. Journal of Applied Psychology, 87, 698-714.

Robinson, S. L. (1996). Trust and breach of the psychological contract. Administrative Science Quarterly, 41, 574-599.

Shadish, W., Cook, T. D., \& Campbell, D. T. (2002). Experimental and quasi-experimental designs for generalized causal inference. Belmont, CA: Wadsworth Cengage Learning. 
Shirom, A. (1989). Burnout in work organizations. In C. L. Cooper \& I. T. Robertson (Eds.), International review of industrial and organizational psychology (pp. 25-48). Oxford, England: John Wiley and Sons.

Shirom, A., \& Melamed, S. (2006). A comparison of the construct validity of two burnout measures in two groups of professionals. International Journal of Stress Management, 13, 176-200. doi:10.1037/1072-5245.13.2.176

Sinclair, R. R., Sears, L. E., Probst, T., \& Zajack, M. (2010). A multilevel model of economic stress and employee well-being. In J. Houdmont \& S. Leka (Eds.), Contemporary occupational health psychology: Global perspectives on research and practice (pp. 1-20). Chichester, England: Wiley-Blackwell.

Skinner, B. F. (1957). Verbal behavior. New York, NY: Applelton.

Soji, K., Cieslak, R., Smoktunowicz, E., Rogala, A., Benight, C. C., \& Luszczynska, A. (2016). Associations between job burnout and self-efficacy: A meta-analysis. Anxiety, Stress, \& Coping, 29, 367-386.

Sverke, M., Hellgren, J., \& Näswall, K. (2002). No security: A meta-analysis and review of job insecurity and its consequences. Journal of Occupational Health Psychology, 7, 242-264.

Taris, T. W. (2006). Is there a relationship between burnout and objective performance? A critical review of 16 studies. Work and Stress, 20, 316-334. doi:10.1080/02678370601065893

ten Brummelhuis, L. L., \& Bakker, A. B. (2012). A resource perspective on the work-home interface: The workhome resource model. American Psychologist, 67, 545-556.

Tetrick, L. E., \& Quick, J. C. (2011). Overview of occupational health psychology: Public health in occupational settings. In J. C. Quick \& L. E. Tetrick (Eds.), Handbook of occupational health psychology (2nd ed., pp. 3-20). Washington, DC: American Psychological Association.

Wang, M., Liu, S., Zhan, Y., \& Shi, J. (2010). Daily work-family conflict and alcohol use: Testing the cross-level moderation effects of peer drinking norms and social support. Journal of Applied Psychology, 95, 377-386.

Williams, L. J., \& O’Boyle, E. (2011). The myth of global fit indices and alternatives for assessing latent variable relations. Organizational Research Methods, 14, 350-369. doi:10.1177/1094428110391472

Xanthopoulou, D., Bakker, A. B., Demerouti, E., \& Schaufeli, W. B. (2009). Work engagement and financial returns: A diary study on the role of job and personal resource. Journal of Occupational and Organizational Psychology, 82, 183-200.

\section{Author Biographies}

Lisa E. Baranik ( $\mathrm{PhD}$, University of Georgia) is an assistant professor of management at the University at Albany, SUNY. Her research focuses on understanding how employees learn and develop, and her research interests include mentoring relationships at work, work motivation and achievement goals, and occupational health psychology, focusing on stressors that employees experience at work. Her work has been published in over 20 peer-reviewed journal outlets including the Journal of Management, Human Performance, Psychological Bulletin, Human Resource Management Review, and the Journal of Vocational Behavior. She currently serves as an editorial board member of the Journal of Vocational Behavior and Occupational Health Science. She enjoys traveling to unconventional locations, gardening with native plants, and spending time with her husband and daughter.

Janelle H. Cheung received her PhD in industrial-organizational psychology, with an emphasis in occupational health psychology, from Clemson University. Her research interests include workplace wellness, employee wellbeing, and occupational health interventions. In her free time, she enjoys hiking, exercising, and spending time with her family.

Robert R. Sinclair (PhD, Wayne State University) is a professor of industrial/organizational psychology at Clemson University where he also currently serves as the graduate program coordinator for the Department of Psychology's $\mathrm{PhD}$ and MS programs. He is a founding member and past president of the Society for Occupational Health Psychology and a fellow of the Society for Industrial-Organizational Psychology and American Psychological Association. He currently serves as the founding editor in chief for Occupational Health Science, an associate editor of the Journal of Business and Psychology, and as an editorial board member of the Journal of Applied Psychology, Journal of Occupational Health Psychology, and Journal of Occupational and Organizational 
Psychology. His current research program focuses on (1) economic stressors (such as job insecurity and perceived income inadequacy) and health; (2) building organizational climates that enhance worker safety, health, and wellbeing; and (3) occupational health risks faced by health-care employees. In his free time, he enjoys spending time with his family, exercise, and playing guitar in his band, the Saints of Circumstance.

Charles E. Lance ( $\mathrm{PhD}$, Georgia Institute of Technology) is a principal at Organizational Research \& Development, LLC; extraordinary professor of Industrial and Organizational Psychology at the University of the Western Cape, South Africa; and professor emeritus at the University of Georgia, Athens, GA. He has published over 100 journal articles in the areas of job performance measurement, assessment center validity, research methods, and structural equation modeling that have appeared in such journals as Psychological Methods, Organizational Research Methods (ORM), Journal of Applied Psychology, Organizational Behavior and Human Decision Processes, Journal of Management, Structural Equation Modeling, and Multivariate Behavioral Research. He has coedited four books including Performance Measurement: Current Perspectives and Future Challenges; Statistical and Methodological Myths and Urban Legends: Doctrine, Verity and Fable in the Organizational and Social Sciences; The Psychology of Assessment Centers; and More Statistical and Methodological Myths and Urban Legends (with Bob Vandenberg). He is a fellow of the Society for Industrial and Organizational Psychology (SIOP) and the American Psychological Association, former president of the Atlanta Society for Applied Psychology, and is a member of the Society for Organizational Behavior. He served 9 years as an associate editor of $O R M$ and has served on the editorial boards of Personnel Psychology, Human Performance, Group \& Organization Management, and ORM. He is married to Dr. Sabine E. Teaver who together manage their rental properties and commune with two dogs and two cats. 